\title{
Techno-economic modelling analysis of microalgae cultivation for biofuels and co-products
}

\author{
F. Madugu \& M. Collu \\ Department of Offshore, Process and Energy Engineering, \\ Cranfield University, $U K$
}

\begin{abstract}
The goal of microalgae for biofuels is not only to replace fossil fuel in quantity but also for the cost to be at parity with the existing fuel stock. Adopting this evolving technology would not only require a combination of technical and economic assessment, but also the confidence of key stakeholders. The main challenge is that there are multiple pathways and logistics related to the entire algal biofuel production chain, and each stage is subject to technical, economic, environmental and policy issues, making it difficult to determine the optimum option. Therefore there is a need for a holistic decision-making tool, which provides a clear choice of direction to all stakeholders. The study initially adopted a multi criteria decision-making approach called TOPSIS, using a case study of five alternatives of algal processes to produce either oil for transport or biogas for electricity generation via a wastewater treatment method. The TOPSIS technique is used to identify the most acceptable alternative that has the maximum distance from the negative ideal and the minimum distance from the positive ideal solution. The result shows the alternative 1 and 2 as the preferred ideal solution among the others. Because the method ranks alternatives according to attributes, it limits the technique to a more defined process and therefore it cannot provide an understanding of feedback effects such as policy, resource availability in a region, and possible scale-up issues affecting the process. These limitations make the TOPSIS a less powerful technique for assessing the overall microalgae supply chain. However it is feasible to adopt the TOPSIS approach and integrate it into a flexible Techno-Economic (TE) model to make a decision over defined processes.

Keywords: biofuels, techno economic modelling analysis, MCDM, co-products.
\end{abstract}




\section{Introduction}

The continuing increase in energy prices together with the environmental impact from the use of fossil fuel has rekindled interest towards the use of sustainable energy to achieve a balanced energy mix. Between 1996 and 2013, oil prices have increased from $\$ 25 /$ barrel to $\$ 115 /$ barrel representing about a threefold increase in price [1]. It has also been reported that global carbon dioxide emission has exceeded the highest threshold of $455 \mathrm{ppm}$ - equivalent, ten years ahead of expectation [2]. Adopting sustainable energy sources such as biofuels can make a significant contribution in mitigating these emissions, thus reducing its contributory impact to global warming.

Algal biomass as a potential renewable source for biofuel production has received significant interest over the years due to their comparative advantages. Such advantages include high lipid content, ability to sequestrate $\mathrm{CO}_{2}$, noncompeting with conventional agricultural produce, compatibility with integrated production re bio-refinery and can be used for wastewater treatment [3]. Algal oil theoretical productivity has been calculated at up to $354,000 \mathrm{~L}^{-h^{-1}} \cdot$.year $^{-1}$ [4] and a realizable production of 46,000 L.ha ${ }^{-1}$.year ${ }^{1}$ has been recorded for a pilot plant to date [5], but the goal of embracing these systems is not only for the algal biofuel to replace fossil fuel in quantity but also for the cost to be at parity or less with existing fuel stock.

Currently no algal biofuel is produced at a price that can compete with fossil fuel due to the multiple pathways/process available, and there are various technical and economic challenges along each step of the process, making it difficult to select the most feasible process for commercial scale production. There is a need to carry out a robust techno-economic modelling and analysis that can span the entire algae-to-biofuel and co-products process chain in a way that it can supply feedbacks on every spatial aspect of the process to support research and investment, leading to a successful realization of the technology. This paper aim to develop a flexible techno-economic model for microalgae processes.

\section{Method and process}

In order to undertake a robust techno-economic analysis of different algal-to-biofuel process, a flexible techno-economic model needs to be developed, that includes not only the technical and economic assessment, but also other aspects that affect the process economy namely environmental and policy issues thus addressing the overall algal-to-biofuel process in a common framework. To achieve that an MCDM approach (multi criteria decision method) called TOPSIS (Technique for Order Preference by Similarity to Ideal Solution) method was adopted and modelled in an excel spreadsheet, the spreadsheet is developed to allow for assessment of many processes in different categories namely technical, economics, environmental and policy. To validate the model, five different alternatives of algal-to-biofuel process have been adopted from literature and used as a case study. 


\subsection{Multi criteria decision method}

Multi criteria decision method (MCDM) is a term for describing different techniques for making complex decision. Bolton and Steward define MCDM as an umbrella term to describe approaches that take explicit account of multiple attributes in helping individuals or group to explore decision that matter [6]. The approach is used when making a decision among different Alternatives with multiple attributes, depending on what are the most important attributes among different alternatives. The aim of adopting an MCDM approach is to evaluate among different algal-to-biofuel processes, and identify the most preferred option, in different assessment categories. There are different techniques available for carrying out a decision making analysis, such as AHP, IPV, TOPSIS, and many others, depending on the complexity of the problem you want to solve, here the Technique for Order of Preference by Similarity to the Ideal solution alternatively called TOPSIS method is adopted.

\subsubsection{TOPSIS}

TOPSIS is an MCDM technique for identifying the solution to finite alternatives based upon concurrent minimization of distance from the positive ideal solution and the maximum distance from the negative ideal solution [7]. With the TOPSIS technique you can incorporate different attributes and assign relative weight to each attribute based on its importance to the respective stakeholders or in this study assessment category. The paper applies the method using the step by step approach from [8].

\section{Step 1: Decision matrix}

The first step is a decision matrix, it is presented as $x=\{x i j, i,=1,2 \ldots, m ;\}$ where $m$ number of selected alternatives $A i$ algal-to-biofuel process $A i(i=1,2 \ldots \ldots, m)$ are evaluated against the $n$ number of selected attribute $C j(j=1,2 \ldots \ldots, n)$.

\section{Step 2: Normalization matrix}

The next step is to normalize the decision matrix, change the attributes from dimensional to non-dimensional to allow for comparison using:

$$
r i j=\frac{x_{i j}}{\sqrt{\sum_{i=1}^{m} x_{i j}^{2}}}
$$

where:

$m=$ alternatives, $n=$ attributes $(m * n)$

$x i j=$ the value of column $i$ and criteria $\mathrm{j}$

$r i j=$ value in row $i$ and in criteria $j$ of the normalized decision matrix.

\section{Step 3: Criteria weight}

Determine the criteria weight (wj) in order to point out their relative importance and multiply the weight by normalization value (rij). The weight can be determined through survey or through other MCDM methods such as AHP. 
1094 Energy Production and Management in the 21st Century, Vol. 2

$$
v_{i j}=w_{j} \times r_{i j}
$$

Step 4: Possible ideal solution

Determine the positive ideal and maximize for every positive ideal (PIS).

$$
A^{+}=\left(v_{1}^{+}, . ., v_{j}^{+}, \ldots, v_{n}^{+}\right)=\left\{\left(\max _{j} v_{i j}|j=1, \ldots, n| i=1, \ldots, m\right\}\right.
$$

Step 5: Negative ideal solution

Determine the negative ideal and minimize for every negative ideal (NIS).

$$
A^{-}=\left(v_{1}^{-}, . ., v_{j}^{-}, \ldots, v_{n}^{-}\right)=\left\{\left(\min _{j} v_{i j}|j=1, \ldots, n| i=1, \ldots, m\right\}\right.
$$

Step 6: Separation from positive and negative ideal

The calculation of the separation of the distance of each measure from the ideal.

$$
\begin{aligned}
& s_{i}^{+}={\sqrt{\sum_{j=1}^{n}\left(v_{j}^{+}-v_{i j}\right)^{2}}}^{2} \\
& s_{i}^{-}={\sqrt{\sum_{j=1}^{n}\left(v_{j}^{-}-v_{i j}\right)^{2}}}^{2}
\end{aligned}
$$

Step 7: Closeness to the ideal solution

The final step of the process is the calculation of the relative closeness of each measure to the ideal.

$$
c_{i}=\frac{s_{i}^{-}}{s_{i}^{+}+s_{i}^{-}}
$$

where: $0<\mathrm{Ci}<1$.

The option closest to the one that is the most preferred option and the farthest to the less preferred option.

\subsection{Categories and criteria/attributes}

\subsubsection{Categories}

To provide input for the TOPSIS model, four assessment categories are selected namely: Technical, Economic, Environmental and Policy, with ten attributes/criteria, the criteria selected are: Capex, Opex, Biomass yield, and Water footprint, operating time, cultivation area, oil produced, biogas produced, energy consumed and overall production cost. The criteria are then assign different weight according to their relative importance in each of the assessment categories, as presented in Table 1. Markings are from less to most important [0.5 = less important; $2=$ most important $]$.

Technical - there are multiple pathways and processes available for algal biofuel production as illustrated in fig 1. And many technical barriers associated with each technology that prevents large scale commercialization. Identifying a 
technology that is cost effective, and can achieve a stable culture, with minimum energy consumption is very challenging [9]. The goal of selecting this category is to assess each technology in term of overall system performance, such as the biomass yield, energy consumption and water footprint. To obtain technical point of view within TOPSIS analysis, these criteria are weighted most important in table 1. Of weighing vectors, Capex, and Opex are comprehensive economic calculation therefore marked as less important.

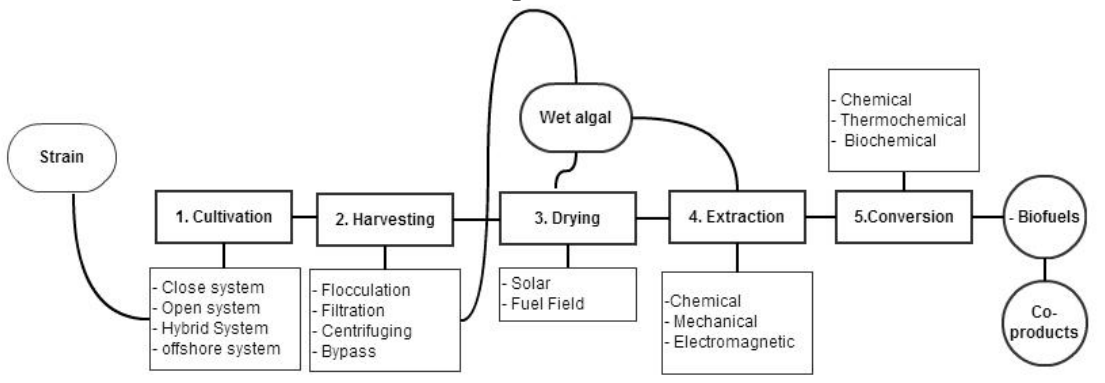

Figure 1: $\quad$ Microalgae to biofuel systems.

Economic - economic analysis would take account of, energy consumed and calculation of capital and operational expenses to reveal the financial investment needed for development of algal biofuel [9]. Although there are many technical challenges that need to be addressed for a feasible development, commercialization still depends on economics to motivate targeted investment irrespective of the achievement in terms of technology and biological breakthrough. Capex and Opex, energy consumed and overall production cost are marked the most important criteria in an economics point of view, followed by the biomass yield as the next important criteria.

Environmental - this category is considered to address life cycle analysis of the systems and processes. Life cycle analysis (LCA) is defined as a cradle to grave approach, it accounts for all materials and environmental impact of a process and this is the most common approach used in assessing sustainability of biofuels. Energy consumed and water required for algae to biofuel production are weighted the most important criteria in this point view.

Policy - presently numerous government policies are established to help promote the use of biofuels, the most common among the policies are: financial incentives, (e.g. tax credits, tariffs), blending requirement and reducing GHG. In the UK one of the main government policies to promote use of biofuels is the Renewable Transport Fuel Obligation[10] for reducing GHG emission from road transport in the UK, where suppliers of biofuels of more than 450,000 litres of fuel into the UK are obligated. It is clear that policies contribute to the realization of biofuels. So, the appropriate choice of policy would differ among different biofuels feedstock's and locations, and because the technology is still at an early stage of development, continuous research would require a number of 
amendments to be made to provide a good policy decision. The weights of criteria are marked according to how they are affected by the policy.

\subsubsection{Criteria/attributes}

The set of attribute/criteria is selected through an intensive literature review and verbal survey with Experts and PhD Research student working in the field of microalgae.

Table 1: Weighting vectors (Vij).

\begin{tabular}{|c|c|c|c|c|c|c|c|c|c|c|}
\hline & نัँ & ठ̊. & 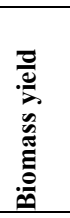 & 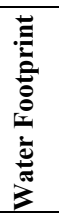 & 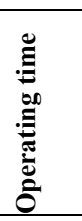 & 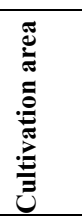 & 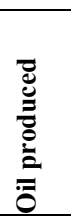 & 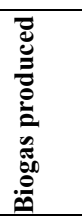 & 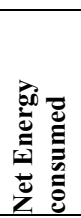 & 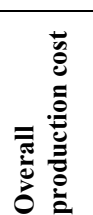 \\
\hline Technical & 0.5 & 0.5 & 2 & 2 & 0.75 & 0.75 & 0.5 & 0.75 & 0.75 & 0.75 \\
\hline Economic & 2 & 2 & 1.5 & 0.5 & 0.75 & 1 & 0.5 & 1.5 & 2 & 2 \\
\hline Environmental & 0.5 & 0.5 & 0.5 & 2 & 0.5 & 1 & 2 & 0.5 & 2 & 0.5 \\
\hline policy & 0.75 & 0.75 & 0.5 & 0.5 & 0.5 & 1.5 & 0.5 & 1.5 & 1.5 & 1.5 \\
\hline
\end{tabular}

Capex/Opex - is the total amount of expenditures incurred for a technology with an aim for a future benefit. This criterion is selected as it accounts for the major cost associated with the facility and can have significant impact on the overall economy [11]. While Opex is the total cost needed to run a facility[12].

Biomass yield - Realizing algae biofuel technology would require maximizing algae biomass yield. It is import to know the amount of biomass recovered to achieve a viable economics of the technology.

Water footprint - is the total amount of water that is consumed and the water that is being lost through evaporation in the whole algal biofuel process. For microalgae production water consumption can become a limitation to its scalability and sustainability. This criterion is selected to evaluate the technologies based on their water consumption and how it affects their environmental advantage [13].

Operation time - because microalgae are photosynthetic in nature, they require sunlight; $\mathrm{CO}_{2}$, water and nutrients to grow. It is obvious that good climate and period of high insolation, and also maximum humidity/rainfall are an important requirement in algae cultivation [14]. Availability of these resources determined the period in which to achieve a favorable productivity, therefore it might not be economical favorable to operate the facility during the period of low productivity. This criterion is selected to determine the effect of length at which the facility operates. 
Cultivation area - is the area covered for microalgae growth including inoculation ponds. This is selected understand impact of scale.

Oil produced - is the extracted algal oil yield from biomass. The oil yield in this study is the output oil produced in alternatives.

Biogas produced - in this study the biogas produced is used for electricity generation, and or produced as co-product by anaerobic digestion after the oil has been extracted. The reason for selecting this criterion is because the processes selected for this study are designed to produce an output of either biogas, and the amount is used to calculate the production cost.

Energy consumed - the energy consumed is the systematic calculation of energy balances. The value of systems mass and energy balance assessment is that it can help assess the overall viability of a given algal biofuel production system and show what steps in the process are most energy intensive [15]. It is a very important criterion when addressing technical and environmental issues.

Production cost - the production cost is the amount per unit of biofuel produced. This criterion is selected to allow comparison of the price with fossil fuel and determine an acceptable price for biofuels when competing with fossil fuel

\section{Case study}

This is a description of the five different alternatives of algal-to-biofuel process assessed, the processes are adopted from .There are 3 major differences between the process, first, the process objective, secondly biofuel output, and thirdly the growth pond area, as presented in Figures 2 and 3. The site is located in southern California where it benefits from high insolation of $6 \mathrm{kwh} / \mathrm{m}^{2-}$ day, and an average evaporation rate of $1 \mathrm{~cm}$. day. The site is assumed to have access to large amount of municipal waste of 51,700-235,000 person equivalent [14]. The facility includes individual pond size of $690 \mathrm{~m}$ by $60 \mathrm{~m}$ and $30 \mathrm{~m}$ wide channel, mixed with paddle wheels at a nominal water velocity of $25 \mathrm{~cm} . \mathrm{sec}$. The technology used is assumed to be a high rate pond for cultivation, inoculation pond is built with plastic liner at $1 \%$ of production area, and biomass harvesting is by bioflocculation followed by sedimentation, drying is done by solar heat, and algal oil recovery is done by hexane extraction. All the processes are assumed to have a recoverable $25 \%$ triacylglyceride from algal biomass and $22 \mathrm{~g} . \mathrm{m}^{-2}$ day biomass productivity with an oil yield of 2100 gal. acre-1. Water and nutrient supplied for cultivation is from municipal wastewater and $\mathrm{CO}_{2}$ is supplied by flue gas from a natural gas fired power plant.

The economics assumes that $100 \%$ of the capital cost is sourced through a bond with an annual payment amount for the life of the bond. It assumed 5\%, 30 year bond to finance construction of the facility, each 100 ha facility will be staffed by 4 senior operators for a total salary of $\$ 375,000$, and 14 full time 
operators for an average salary of $\$ 41,100$ per year. The number of full time staff differs among different facility.

The average energy consumed to operate a 100 ha facility is 100 mwh.day. The major consumption is from the high rate pond with $49 \%$ of the total energy consumed, followed by water pumping at 19\%, harvesting pumping $13 \%$, blowers for flue gas at $10 \%$ and solvent oil extraction $9 \%$. More detail on the case study can be found in Lundquist et al. [14].

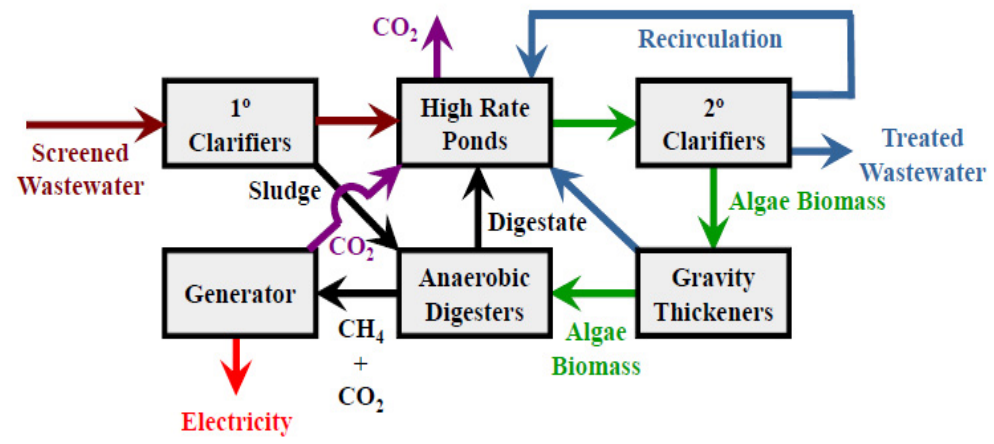

Figure 2: Process schematic for alternative 1, 2 and 4 (wastewater treatment emphasis with production of biogas only).

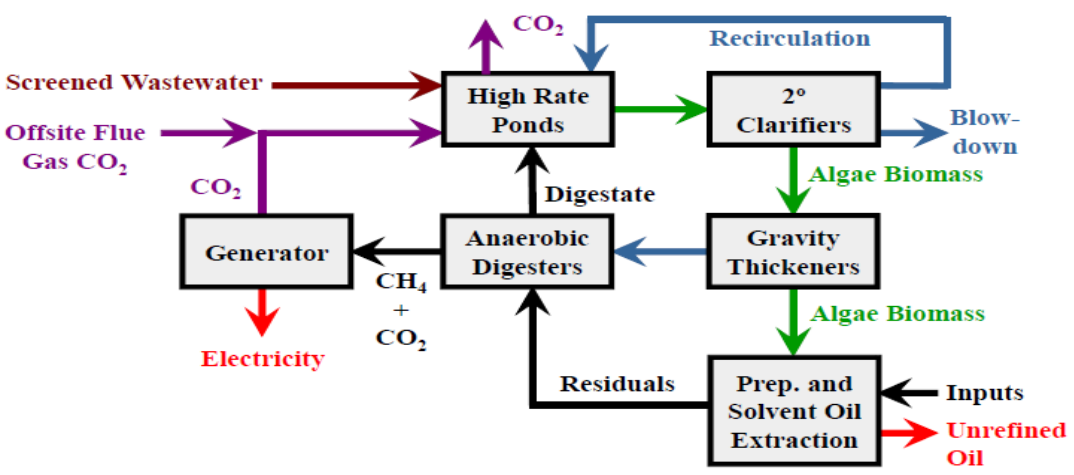

Figure 3: Process schematic for alternative 3 and 5 (biofuel - emphasis with both oil and biogas).

\section{Results}

The results are presented in two categories, first is the output from the TOPSIS model and the second result is the techno-economic output of the case study. 


\subsection{TOPSIS result}

TOPSIS model output provides 2 different results, first ranking of the alternatives in each category and the overall rank in all categories.

The result for Technical category shows a value of $0.509-0.4$, with average value of 0.505 , alternative 1 ranked the highest number that is closest to one. It is notable that both alternative 2 and 4 values do not have much difference as compared 1.

The economic output ranges from $0.56-0.45$ and an average value of 0.56 . For the economic category, alternative 2 is ranked the most preferred alternative closest to 1 , followed by alternative 4 with 0.561 . In this case alternative 4 is more economically viable than alternative 1 in the case of technical preferences. The preferred alternative in an environment category is alternative 1 , in this category all the alternatives show greater value that is higher than the ranking in technical and economic category, meaning the all the alternatives are environmentally favourable.

The preferred alternative in the policy category is 1 with a ranking value of 0.610 , followed by alternative 2 and 4 at 0.590 .

Comparing all the categories the overall result shows that alternative 1 and 2 are the most preferred alternatives in all perspectives. Alternative 5 is the less preferred alternative in all perspectives.

Table 2: Overall ranking based on category.

\begin{tabular}{lllll}
\hline & T & E & E & P \\
\hline A1 & 0.509082 & 0.553185 & 0.725443 & 0.601997 \\
A2 & 0.504794 & 0.565985 & 0.714117 & 0.590946 \\
A3 & 0.488196 & 0.429459 & 0.700314 & 0.499825 \\
A4 & 0.504697 & 0.561715 & 0.725343 & 0.590489 \\
A5 & 0.474528 & 0.5 & 0.206288 & 0.21477 \\
\hline
\end{tabular}

\subsection{Case study result}

The output of the case study obtained for each of the selected criteria is presented in table 4, and input to the decision matrix of the TOPSIS model, they are then translated in ranking order to identify the overall viable option. For the case study the results like the TOPSIS also show that alternatives 1 and 2 to be most economically favourable options. Both 1 and 2 are wastewater emphasis, therefore use wastewater to make up for water loss and nutrient, they operate all year round unlike the biofuel alternatives 3, 4 and 5 that are not operated year round due to low productivity during periods of winter which results to low economics and energy balance, this favours 1 and 2 to produced higher biomass productivity and biofuel produced. The overall production cost for 1 and 2 is much more competitive as to the current price of oil. Whereas 3 and 4 only use wastewater as supplementary making them less economically favourable, 5 
which is similar 3 (100 ha) but 4 (400 ha) times bigger reduces cost of production by $1 / 3$ due to economies of scale. Energy produced by all alternatives accounts for more than the energy consumed making them environmentally favourable, this also match with the TOPSIS result. Policy issues are cost related i.e. permit, legal, insurance and management are all included in Capex and Opex calculation.

Table 3: Decision matrix $(X)$.

\begin{tabular}{|c|c|c|c|c|c|}
\hline & A1 & A2 & A3 & A4 & A5 \\
\hline Capex $(\mathrm{m} / \$)$ & 35722 & 26044 & 30606 & 2132 & 101585 \\
\hline Apex $(\mathrm{m} / \$)$ & 21 & 15.9 & 28.1 & 14.7 & 8.09 \\
\hline Biomass yield (Mt/yr) & 7440 & 7440 & 7200 & 6730 & 28900 \\
\hline Water footprint (ML/yr) & 22740 & 22740 & 3160 & 2820 & 13600 \\
\hline Operating time $(\mathrm{mo} / \mathrm{yr})$ & 12 & 12 & 10 & 8 & 10 \\
\hline Cultivation area (ha) & 100 & 100 & 100 & 100 & 400 \\
\hline Oil produced (bbl/yr) & 12770 & 0 & 12300 & 0 & 49300 \\
\hline Biogas produced $\left(10^{6} \mathrm{~m}^{3} / \mathrm{yr}\right)$ & 2.56 & 3 & 1.73 & 2.03 & 6.95 \\
\hline Net energy consumed & 410 & 410 & 410 & 410 & 1640 \\
\hline Overall production cost $(\$)$ & 28 & 0.17 & 332 & 0.72 & 240 \\
\hline
\end{tabular}

\section{Conclusions}

Applying TOPSIS method as a decision making tool for Techno-economic modelling of algal production chain has a limitation. Because the TOPSIS method ranks alternatives according to attribute values from chosen criteria, it limits the technique to a more defined process, therefore cannot provide an understanding of feedback effects such as policy, resource availability in a region, and possible scale-up issues affecting the process, these limitations makes the TOPSIS a less powerful technique for assessing overall microalgae supply chain. Another major factor affecting the TOPSIS is the dependant of the result on the weighting vectors, as opinion may vary greatly among different stakeholders in the field, as issues with microalgae cultivation differ between regions and location. However it is feasible to adopt the TOPSIS approach and integrated it in a flexible TE Model to make decision over defined processes. Developing a flexible techno-economic model that can meet the goal of a viable, reliable and efficient microalgae to biofuels and co-product is possible if various assessment models are adopted to provide input and then translated to a define output. Future work for this study would include survey through a questionnaire to address a wider opinion, other models that can be adopted includes LCA model and algae growth model.

\section{Acknowledgements}

The authors acknowledge the financial support of the Petroleum Technology Development Fund and Cranfield University. 


\section{References}

[1] Amer, L., Birendra, A. and Pellegrino, J. (2011), "Technoeconomic analysis of five microalgae-to-biofuels processes of varying complexity", Bioresource technology, vol. 102, no. 20, pp. 9350-9359.

[2] Schenk, M. P., Skye, R. T., Evan, S., Ute, C. M., Jan, H. M., Clemens, P., Olaf, K. and Ben, H. (2008), "Second Generation Biofuels: High-Efficiency Microalgaefor Biodiesel Production", vol. 10.1007 /s12155-008-9008-8, no. 43, pp. 1-20.

[3] Brennan, L. and Owende, P. (2010), "Biofuels from microalgae - A review of technologies for production, processing, and extractions of biofuels and co-products", Renewable and Sustainable Energy Reviews, vol. 14, no. 2, pp. 557-577.

[4] Weyer, K. M., Daniel, R. B., Al, D. and Bryan, D. W. (2009), "Theoretical Maximum Algal Oil Production", pp. 3:204-213.

[5] Liaw, B., Jason, Q., Bryan, W. and Thomas, B. (2010), "Net Energy and Greenhouse Gas Emission Evaluation of Biodiesel Derived from Microalgae", vol. 44, pp. 7975-7980.

[6] Valerie Belton, T. S. (2002), Multiple criteria decision analysis: an integrated approach, 2nd ed, Kluwer Academic Publishers, Massachusetts, USA.

[7] Olson, D. L. (2004), "Comparison of weights in TOPSIS models", Mathematical and Computer Modelling, vol. 40, no. 7-8, pp. 721-727.

[8] Wang, J., Jing, Y., Zhang, C. and Zhao, J. (2009), "Review on multicriteria decision analysis aid in sustainable energy decision-making", Renewable and Sustainable Energy Reviews, vol. 13, no. 9, pp. 2263-2278.

[9] Fishman, D., Majumdar, R., Morello, J., Pate, R. and Yang, J. (2010), National algal biofuel technology roadmap. US Department of energy and Renewable Energy, Biomass Program, U.S. DOE, Maryland, USA.

[10] RTFO (2012), Renewable Transport Fuel Obligation, available at: https://www.gov.uk/renewable-transport-fuels-obligation (accessed 06/2013).

[11] Chisti, Y. (2007), "Biodiesel from microalgae", Biotechnology Advances, vol. 25, no. 3, pp. 294-306.

[12] Benemann, J. R. and Oswald, W. (1996), Systems and Economic Analysis of Microalgae Ponds for Conversion of CO to Biomass, US. Department of Energy, USA.

[13] Delrue, F., Setier, P., Sahut, C., Cournac, L., Roubaud, A., Peltier, G. and Froment, A. (2012), "An economic, sustainability, and energetic model of biodiesel production from microalgae", Bioresource technology, vol. 111, no. 0, pp. 191-200.

[14] Lundquist, T. J., Woertz, I. C., Quinn, N. W. T. and Benemann, J. R. (2010), A Realistic Technology and Engineering Assessment of Algae Biofuel Production, Energy Biosciences Institute University of California, California. 
1102 Energy Production and Management in the 21st Century, Vol. 2

[15] Jorquera, O., Kiperstok, A., Sales, E. A., Embiruçu, M. and Ghirardi, M. L. (2010), "Comparative energy life-cycle analyses of microalgal biomass production in open ponds and photobioreactors", Bioresource technology, vol. 101, no. 4, pp. 1406-1413. 